\title{
17.0\% Aperture Area Module Efficiency using Large mc-Si Metal-Wrap-Through Cells
}

\author{
Arthur W. Weeber ${ }^{a}$, Ian J. Bennett ${ }^{b}$, Caroline Tjengdrawira ${ }^{c}$, Machteld W.P.E. \\ Lamers $^{d}$, Agnes A. Mewe ${ }^{\mathrm{e}}$, Ingrid G. Romijn ${ }^{\mathrm{f}}$, and Paul C. de Jong ${ }^{g}$ \\ ECN Solar Energy, P.O. Box 1, 1755 ZG Petten, The Netherlands \\ a'weeber@ecn.nl, bbennett@ecn.nl, ${ }^{\mathrm{a}}$ tjengdrawira@ecn.nl, damers@ecn.nl, ${ }^{\mathrm{e}} \mathrm{mewe} @ e c n . n l$, \\ 'romijn@ecn.nl, ${ }^{9}$ p.dejong@ecn.nl
}

Keywords: multicrystalline silicon, modules, back-contact cells, conductive adhesives.

\begin{abstract}
An integrated cell and module technology based on metal-wrap-through (MWT) cells has been developed and demonstrated. $243 \mathrm{~cm}^{2}$ large and $160 \mu \mathrm{m}$ thin multicrystalline silicon MWT cells were made with a best cell efficiency of $17.9 \%$. From 36 cells with an average efficiency of $17.8 \%$ a full-size module was made with an efficiency of $17.0 \%$ (aperture area). The module was made using a conductive rear-side foil with conductive adhesive for the interconnection. The module was constructed using a dedicated module manufacturing line that is designed to be able to work with extremely thin cells and provide a high through-put of one 60 cell module per minute.
\end{abstract}

\section{Introduction}

To reduce costs for solar electricity it is needed to reduce material consumption, to achieve high efficiencies and to apply high-throughput manufacturing technologies. The first can be realized by using thinner wafers and reducing the consumption of metal (especially Ag), the second by applying advanced process technology and going to back-contact cells, and the third by for example using new module manufacturing technologies and integrating the cell and module design. Cost calculations, taking into account a variety of high-efficiency cell and module concepts, showed that for multicrystalline silicon PV technology $17.0 \%$ cell efficiency is needed to reach $1 € / \mathrm{Wp}$ [1]. Furthermore, the cell efficiency in the module should only be $0.1-0.3 \%$ absolute less than these values. At ECN cell research has been performed on metal-wrap-through (MWT) cells based on multicrystalline silicon. A novel method of module manufacture using large and thin mc-Si MWT cells was developed to integrate the cell and module concept. This technology is based on a patterned conductive foil that is used as the substrate, and serves as interconnection material for MWT cells [2]. A pilot production line was built with the potential to manufacture one module per minute. An interconnection technology was developed using conductive adhesives for the interconnect allowing a combined interconnection and lamination step in module fabrication. In this paper we will describe the cell and module concept in more detail. The technology developed enables the use of thin wafers, results in higher efficiencies and can be applied on large scale.

\section{Metal-Wrap-Through cell design and solar cell results}

The MWT cell design developed at ECN is presented in Fig. 1. Advantages of this cell design are:

- Better appearance, and higher packing density in the module possible;

- Less metallization coverage that enhances the current output;

- Resistance losses independent on the cell size, but only dependent on the size of the unit cell;

- Back-contacted which does not require tabbing and enables the introduction of new module technologies to reduce the efficiency loss between cell and module;

- Cell technology the same as current manufacturing technology, except for hole drilling and junction isolation at the rear. 

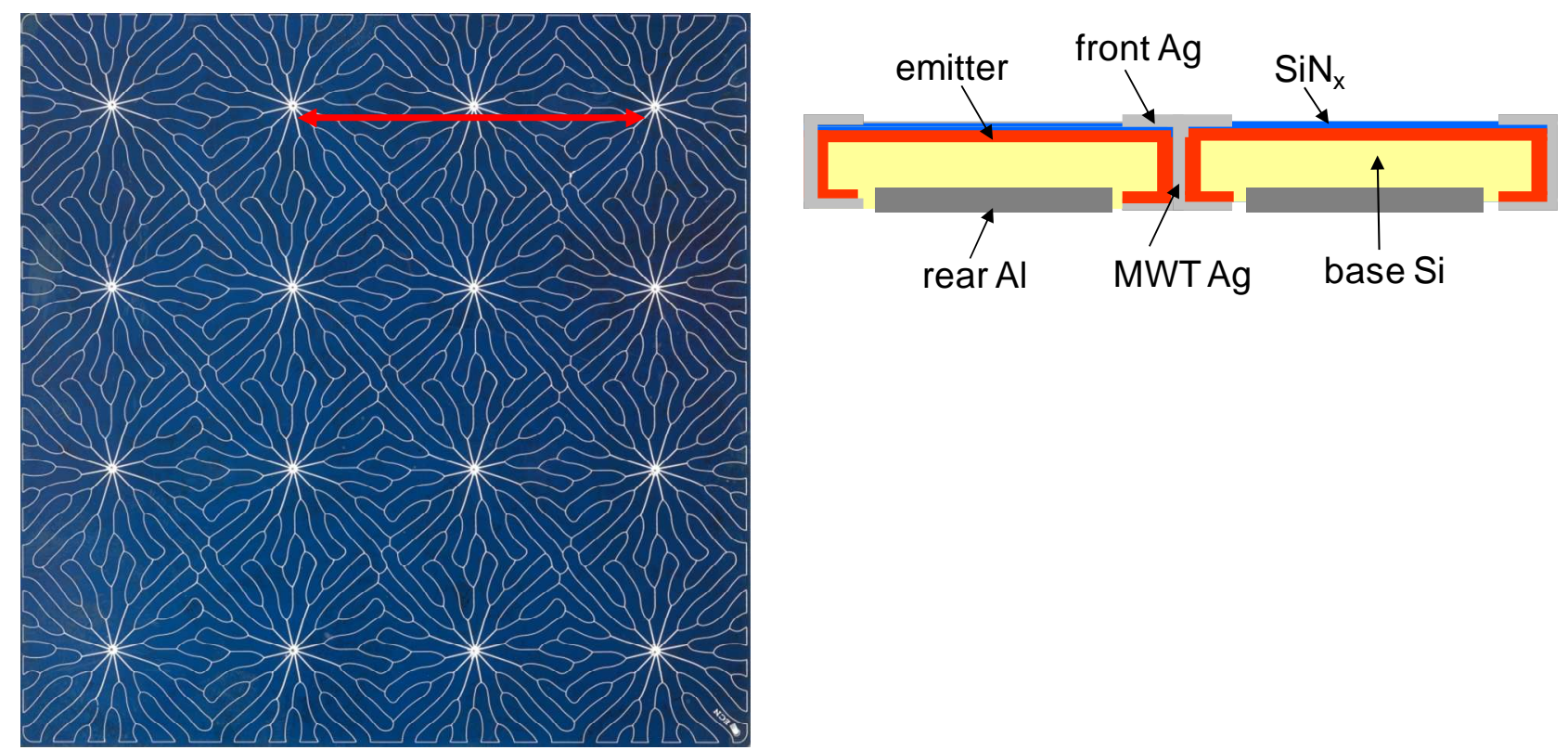

Figure 1: Design of an MWT cell at the left. The current is collected at 16 spots where holes filled with metallization lead this current to the rear side of the cell. A schematic cross-section indicated by the arrow is presented at the right. The metallization pattern is a Sunweb ${ }^{\circledR}$ design which is registered and owned by Solland Solar.

The cell processing used is a so-called standard firing-through process based on screen-printing. As wafer material optimized $p$-type multicrystalline silicon material from REC Wafer was used. The first step in the cell process is laser drilling of the holes. Then, the saw damage was removed which simultaneously resulted in a textured front surface. For multicrystalline wafer material an advanced isotexturing process based on $\mathrm{HF} / \mathrm{HNO}_{3}$ was applied which resulted in low reflectance [3]. Then, an advanced emitter process to form the $p n$-junction was carried out using $\mathrm{POCl}_{3}$ as a phosphorous source and tube furnace diffusion [4]. The antireflection coating (ARC) was deposited using a microwave remote Plasma Enhanced Chemical Vapour Deposition (PECVD) tool. The $\mathrm{SiN}_{\mathrm{x}}: \mathrm{H}$ coating acts as passivating layer as well, and reduces the recombination losses at the front surface and in the bulk of the solar cell. The latter occurs during sintering of the metallization. During this sintering step hydrogen from the ARC diffuses into the bulk of the silicon where it can passivate defects and impurities. Ag metallization in the holes, at the rear, and at the front was performed by screen-printing. As front side metallization grid we used is the Sunweb® pattern [5] which is shown in Fig. 1, as well as a cross section of the cell. Base Ag contact points at the rear are needed for interconnection. The new front side design and the small Ag base contact pads at the rear reduce the Ag consumption significantly compared to conventional H-pattern cells. The remaining base area at the rear side was contacted with $\mathrm{Al}$, which was also applied by screen-printing. During sintering a so-called back surface field (BSF) is formed, which reduces the recombination losses at the rear surface. Finally, the junction has to be isolated using laser scribing. The laser scribing needs to be carried out around the holes and at the edge of the cells. Another method for junction isolation is wet-chemical etching of a phosphorous containing layer parasitically deposited at the rear side. We applied the wet-chemical etching to obtain the higher efficiencies. More details can be found in $[4,6,7]$.

In Table 1 the cell results are presented. The cell size is $156 \times 156 \mathrm{~mm}^{2}\left(243 \mathrm{~cm}^{2}\right)$, and the cell thickness is about $160 \mu \mathrm{m}$. The best cell has an efficiency of $17.9 \%$, and the average efficiency of the best 36 cells is $17.8 \%$. The same cell processing was carried out on thinner (down to $120 \mu \mathrm{m}$ ) material as well, and no problems were observed. These results demonstrate that high efficiency cells can be obtained with thinner material and less Ag consumption. 
Table 1: Cell parameters of the best multicrystalline Si MWT cell and the average values of 36 MWT cells. The cell size is $156 \times 156 \mathrm{~mm}^{2}$ and cell thickness is about $160 \mu \mathrm{m}$.

\begin{tabular}{|l|c|c|c|c|}
\hline & $\mathrm{I}_{\mathrm{SC}}(\mathrm{A})$ & $\mathrm{V}_{\mathrm{OC}}(\mathrm{mV})$ & $\mathrm{FF}$ & $\eta(\%)$ \\
\hline Best cell & 8.86 & 632 & 0.778 & 17.9 \\
\hline Average 36 cells & 8.85 & 631 & 0.774 & 17.8 \\
\hline
\end{tabular}

\section{Module design for Metal-Wrap-Through cells}

To fully benefit from the advantages of MWT cells, an alternative module manufacturing technology is required. At ECN, a method using a patterned conductive foil as the module substrate was developed. The foil is similar to a standard TPT back-sheet foil with an additional inner layer consisting of a conductive sheet. The conductive sheet is patterned to match the contact points on the rear of the back-contact cell which results in a series interconnection of the cells on the foil. The cells are placed on the foil using a method analogous with pick-and-place technology used for SMD in the electronics industry. This reduces cell handling to just one pick-and-place step so limiting potential damage to the cells. Our integrated MWT cell and module design can be seen in Fig. 2. The rear side foil and contact pads for interconnection are clearly visible.

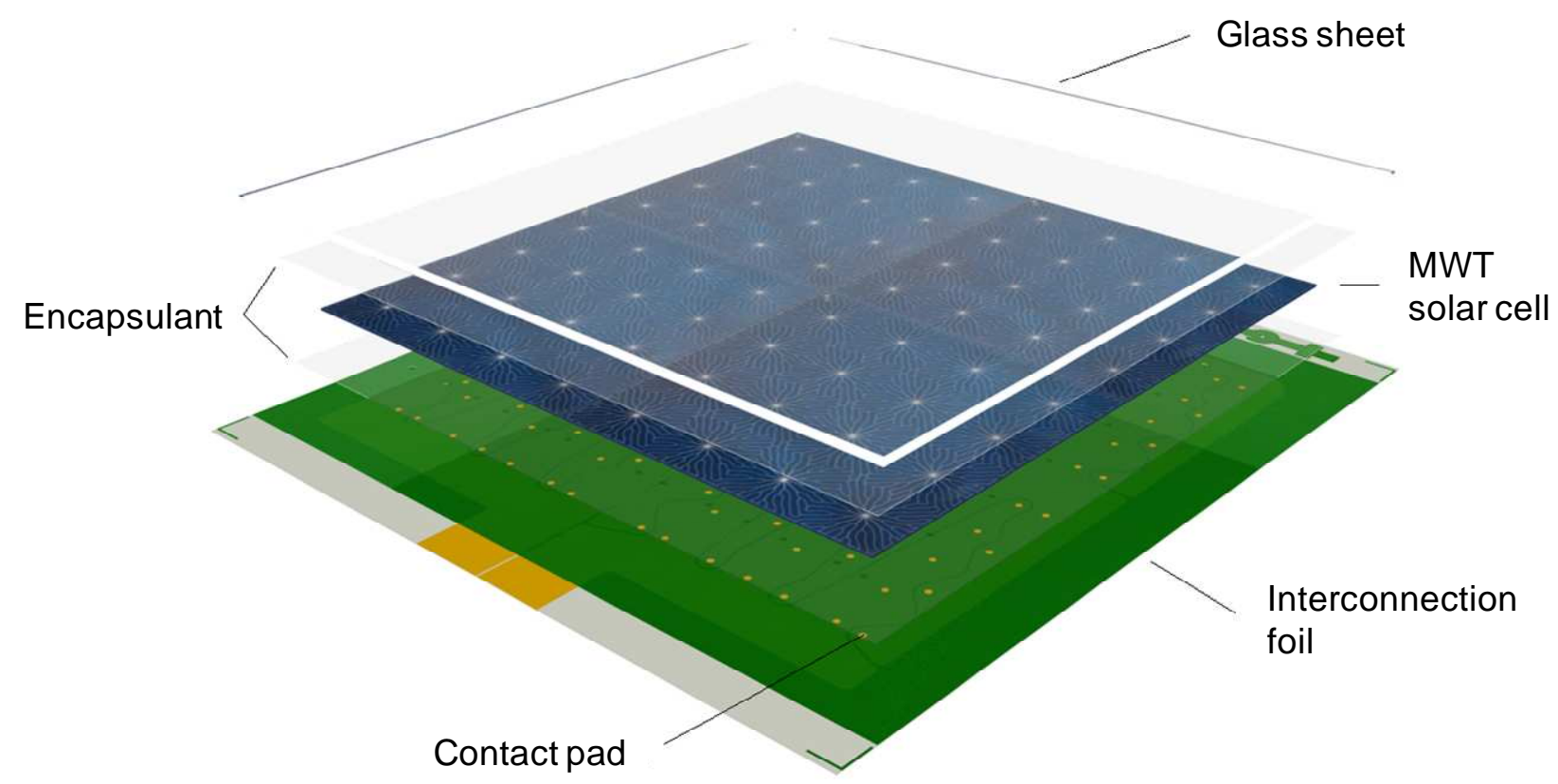

Figure 2: Integrated MWT cell and module design. The rear side foil is used for series interconnection of MWT cells. Contact pads on the foil correspond to the contacts on the cell.

Contact between the cells and the conductive foil is formed using a conductive adhesive. The adhesive is printed on the foil at contact points corresponding to the contact pattern on the rear of the MWT cell. Conductive adhesive was chosen as the contact method due to its low processing temperature and the greater mechanical flexibility of the contact relative to a soldered joint. Both factors contribute to a lower stress at the contact with the cell which is important when working with large and thin cells. The processing temperature of the conductive adhesive matches the lamination temperature of the encapsulant (EVA). This allows a combined curing and lamination cycle with no need for a separate contact processing step. 
However, interconnection by conductive adhesives is a new method and has to tested thoroughly before the technology can be applied on large scale. Damp heat and thermal cycling tests were applied to conductive adhesive interconnections and compared to conventional soldering [8] using conventional H-pattern multicrystalline Si cells. The results can be seen in Fig. 3 and it can be concluded that with respect to damp heat and thermal cycling interconnection using conductive adhesives is as least as good as soldering.
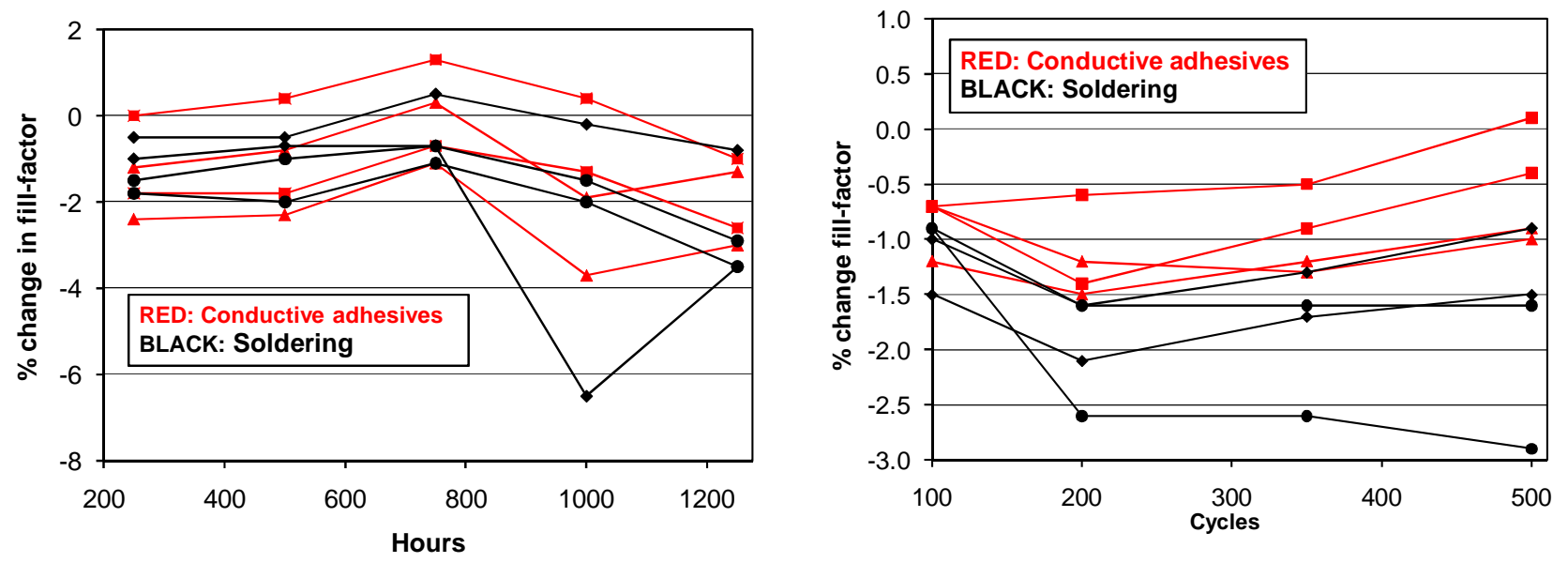

Figure 3: Change in FF during damp heat testing (left) and after thermal cycling (right).

\section{Module manufacturing technology and module results}

Module manufacture was performed on a pilot line at ECN (Fig. 4). The line consists of five stations performing the following steps [9]:

Station 1: The patterned conductive foil is placed on a carrier plate which transports the foil through the module build process. The foil is held in place by vacuum.

Station 2: The conductive adhesive is printed on the foil. The complete foil can be printed in less than one minute. A 36 cell foil requires 1116 dots of conductive adhesive.

Station 3: The first sheet of encapsulant (EVA) needs to be perforated at the positions where the conductive adhesive has been printed to allow contact with the cells. This station can perforate and place a complete EVA sheet in less than one minute. The foil is then automatically placed over the conductive foil without damaging or smearing the conductive adhesive dots.

Station 4: The cells are individually picked from a stack by a robot and placed at a preprogrammed position on the foil with the contacts on the cell making contact with the conductive adhesive (Fig. 5). A vision system checks the cell integrity and orientation. The module assembly is then returned to station 3 for a second sheet of EVA (without holes) and a sheet of glass. In a production line, additional in-line stations would be included for these operations.

Station 5: For lamination the glass sheet needs to be at the bottom of the module stack. A conveyer belt attached to a pneumatic arm is used to invert the carrier with the module stack in place. The module is then fed out of the pilot line to be placed in the laminator.

Lamination is subsequently performed to create the monolithic assembly. The module is then finished by attachment of a frame and junction box.

In a production line further automation can be implemented, for example, automatic feed in of materials. A production line will also be fitted with a number of carriers with a return system taking a carrier back to the start of the line after module build up is complete. A production line has a potential through-put rate of one module per minute for 60 cell modules. This is up to 8 times faster than a conventional tabber-stringer which is used to interconnect H-patterned solar cells.

A full-size module was made from the 36 cells with an average efficiency of $17.8 \%$ (see above), and using the technology described above. An anti-reflection coating was used on the glass sheet at 
the front of the module. This coating was provided by DSM (DSM Innovation Center B.V., Geleen, The Netherlands). Solar glass without a coating transmits up to $92 \%$ of light while with the antireflection coating up to $96 \%$ of light was transmitted, thus increasing the light absorbed by the cells.

The module characteristics were determined independently by JRC-ESTI and can be found in Table 2. These results can also be found in the record efficiency table of Green et al. [10]. The relatively low loss in efficiency between cells and module is due to the higher packing density and the lower resistance losses in the module components. The loss in efficiency is depicted in Table 3 as well. In this table the $\mathrm{V}_{\mathrm{OC}}$ and efficiency are related to the cell output (and area) in the module. These characteristics can be directly compared to the ones in Table 1 . The main difference is the slightly lower FF in the module.

Table 2: Characteristics of the full-size module.

\begin{tabular}{|c|c|c|c|c|}
\hline$\eta(\%)$ & Aperture area $\left(\mathrm{cm}^{2}\right)$ & $\mathrm{V}_{\mathrm{OC}}(\mathrm{V})$ & $\mathrm{I}_{\mathrm{SC}}(\mathrm{A})$ & FF \\
\hline 17.0 & 8885 & 22.67 & 8.86 & 0.750 \\
\hline
\end{tabular}

Table 3: Average cell output in the module.

\begin{tabular}{|c|c|c|c|c|}
\hline$\eta(\%)$ & Aperture area $\left(\mathrm{cm}^{2}\right)$ & $\mathrm{V}_{\mathrm{OC}}(\mathrm{V})$ & $\mathrm{I}_{\mathrm{SC}}(\mathrm{A})$ & $\mathrm{FF}$ \\
\hline 17.2 & 243 & 0.630 & 8.86 & 0.750 \\
\hline
\end{tabular}

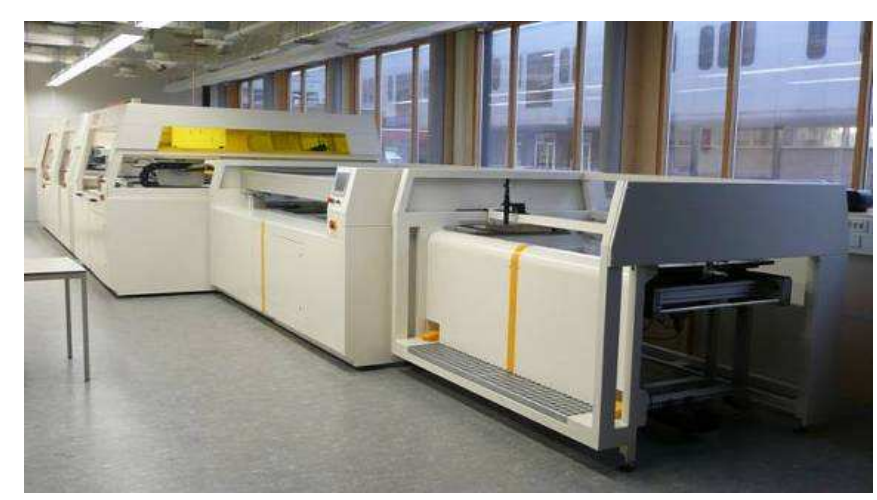

Figure 4: The module pilot line at ECN. The module building starts at station 1 at the front of the picture with positioning of the foil on the carrier plate.

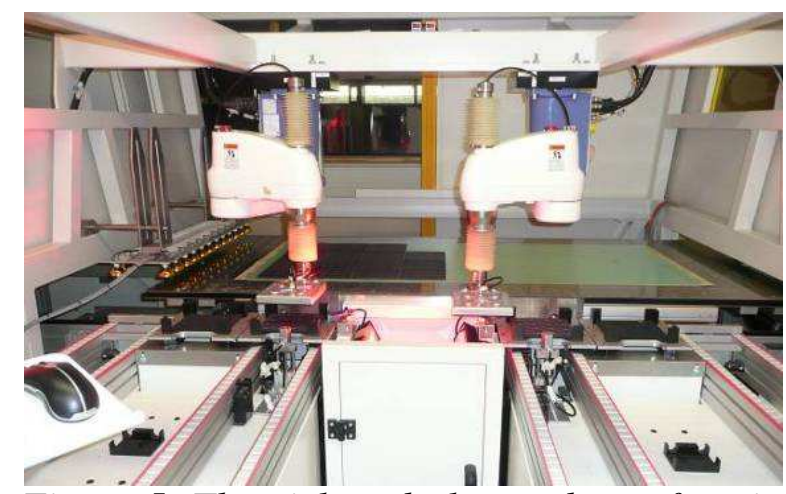

Figure 5: The pick-and-place robots of station 4. The robots pick cells from a stack and place them on the conductive foil which has been printed with conductive adhesive. A vision system between the robots checks the integrity and orientation of the cells. 


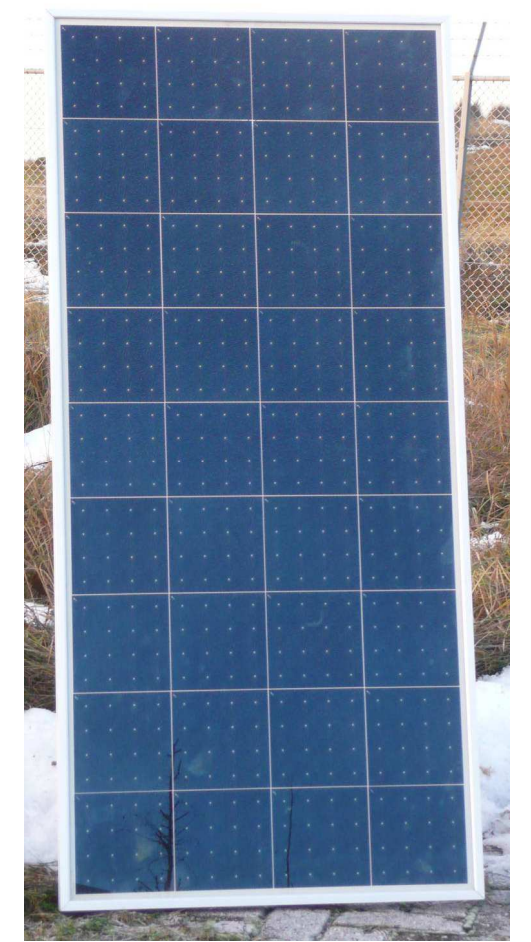

Figure 6: Full-size MWT module with 17.0\% aperture area efficiency. The characteristic cell structure is clearly visible.

The module technology was proven using thinner cells as well. Full-size modules were made using $120 \mu \mathrm{m}$ thin and large MWT solar cells. They were made without cell breakage [4].

The technology demonstrates that thin and large cells can be assembled using a process that is suitable for high production rates, which enables competitive prices for solar electricity.

\section{Conclusions}

$17.0 \%$ module efficiency (aperture area, $8885 \mathrm{~cm}^{2}$ ) was reached using ECN's integrated MWT cell and module design. The full-size module was made using 36 large $\left(156 \times 156 \mathrm{~mm}^{2}\right)$ and thin $(160$ $\mu \mathrm{m})$ multicrystalline Si MWT solar cells with an average efficiency of $17.8 \%$. A conductive foil and conductive adhesives were used for interconnection. The module technology was demonstrated using a pilot line and the manufacturing process steps were proven on cells with thickness down to $120 \mu \mathrm{m}$. No cell breakage was observed during module fabrication. A manufacturing line based on this pilot line has a potential throughput rate of 1 module per minute for a 60 cell module.

\section{Acknowledgement}

This work was partly carried out within the Integrated Project Crystal Clear, which was funded by the European Commission under contract nr. SES6-CT-2003-502583. REC is acknowledged for the wafer supply and financial contribution. Solland Solar is recognized that we could use the Sunweb® metallization pattern. DSM is acknowledged for their anti-reflection coating on the glass sheet. We thank JRC-ESTI for measuring the module characteristics.

\section{References}

[1] C. del Canizo, G. del Coso and W. C. Sinke: Prog. Photovolt: Res. Appl. Vol. 17 (2009) p. 199

[2] P. C. de Jong, D. W. K. Eikelboom, R. Kinderman, A. C. Tip, J. H. Bultman, M. H. H. Meuwissen, M. A. C. J. van den Nieuwenhof: Proceedings of the $19^{\text {th }}$ European Photovoltaic Solar Energy Conference and Exhibition, Paris, France, 7-11 June, 2004 
[3] C.J.J. Tool, G. Coletti, F.J. Granek, J. Hoornstra, M. Koppes, E.J. Kossen, H.C. Rieffe, I.G. Romijn, A.W. Weeber: Proceeding of the $20^{\text {th }}$ European Photovoltaic Solar Energy Conference and Exhibition, Barcelona, Spain, 6-10 June, 2005

[4] A.A. Mewe, M.W.P.E. Lamers, I.J. Bennett, M. Koppes, I.G. Romijn, A.W. Weeber: Proceeding of the $24^{\text {th }}$ European Photovoltaic Solar Energy Conference and Exhibition, Hamburg, Germany, 21-25 September, 2009

[5] The Sunweb® pattern is registered and owned by Solland Solar, information on http://www.sollandsolar.com

[6] M.W.P.E. Lamers, E.E. Bende, I.J. Bennett, M. Koppes, E.J. Kossen, A.A. Mewe, I.G. Romijn, C. Tjendrawira, P.C. de Jong, A.W. Weeber: Proceeding of the $19^{\text {th }}$ Photovoltaic Science and Engineering Conference, Jeju, Korea, 9-13 November, 2009

[7] M.W.P.E. Lamers et al.: to be presented at the $25^{\text {th }}$ Photovoltaic Solar Energy Conference and Exhibition $\left(5^{\text {th }}\right.$ World Conference on Photovoltaic Energy Conversion), Valencia, Spain, 6-10 September 2010

[8] I. J. Bennett, P. C. de Jong, M. J. H. Kloos, C. N. J. Stam, A. Henckens, J. Schuermans, R. J. Gomez, P. Sánchez-Friera, B. Lalaguna and H. Schmidt: Proceeding of the $22^{\text {nd }}$ European Photovoltaic Solar Energy Conference and Exhibition, Milan, Italy, 3-7 September, 2007

[9] I. J. Bennett, C. Tjengdrawira, A. A. Mewe, M. W. P. E. Lamers, P. C. de Jong and A. W. Weeber: Proceeding of the $24^{\text {th }}$ European Photovoltaic Solar Energy Conference and Exhibition, Hamburg, Germany, 21-25 September, 2009

[10] M.A. Green, K. Emery, Y. Hishikawa and W. Warta: Prog. Photovolt: Res. Appl. Vol. 18 (2010) p144 